\title{
Temporal trends in elephant Loxodonta africana numbers and densities in northern Botswana: is the population really increasing?
}

\author{
Jessica Junker, Rudi J. van Aarde and Sam M. Ferreira
}

\begin{abstract}
The apparent increase in elephant Loxodonta africana numbers in northern Botswana is of concern because it may affect other species. We compared changes in population growth rates based on elephant numbers and densities over 1973-2004. Population estimates and survey details extracted from published and unpublished sources allowed us to calculate growth rates. From 1973 to 1993 growth rate was positive when based on elephant numbers but did not differ from zero when calculated for densities. This discrepancy may be because of the significant increase in survey area during the same period. In contrast, none of the growth rates differed from zero for time series between 1996 and
\end{abstract}

2004, when the size of the survey area varied little. We propose two explanations for these results. The first suggests that the population did not grow, while the second proposes that the population expanded its range and increased in size. Notwithstanding, an equilibrium model best explained the variance in dry season estimates of elephant numbers for the complete time series. Such apparent density-dependence could be disrupted by any artificial reduction of numbers through culling as a management option in northern Botswana.

Keywords Botswana, density, elephant, intrinsic growth rate, Loxodonta africana, number.

\section{Introduction}

Botswana supports the largest population of African elephant Loxodonta africana in any country (Cumming \& Jones, 2005), and numbers are apparently increasing (Gibson et al., 1998; Spinage, 1990; Blanc et al., 2003; Cumming \& Jones, 2005). This has generated concern about potential adverse effects on vegetation and on cooccurring species (Sommerlatte, 1976; Colegrave et al., 1992; Ben-Shahar, 1997; Skarpe et al., 2004) and the likely increase in human conflict (Bengis, 1996). In such cases population management is often mooted as a precaution.

There is a general assumption that elephant numbers and impact are directly related (van Aarde et al., 2006; van Aarde \& Jackson, 2007). This may not necessarily be the case because density and, more specifically, the intensity of land use, may dictate impact. For instance, elephants in areas with a high density of water sources have smaller home ranges than those in areas with a low density of water sources (Grainger et al., 2005). In small home ranges elephants may use specific parts of their ranges more intensely than in large home ranges and

Jessica Junker, Rudi J. van Aarde (Corresponding author) and Sam M. Ferreira Conservation Ecology Research Unit, Department of Zoology and Entomology, University of Pretoria, Pretoria 0002, South Africa. E-mail rjvanaarde@zoology.up.ac.za

Received 4 October 2006. Revision requested 14 November 2006 Accepted 21 December 2006. First published online 14 January 2008. therefore impact may be more intense. Thus, it may be more appropriate to define elephant impact in terms of range utilization functions or densities rather than population numbers per se. This is particularly important for open populations where movement is not restricted by fences. In such cases, elephant movements may complicate the interpretation of trends in population size because an increase in number may not equate to an increase in density if the population expands its range. The northern Botswana elephant population may represent such a case.

Growth rates based on time series data may serve as a first estimate of population trends but the interpretation of these trends may be constrained by methodological aspects. For instance, an expansion of survey area over time could return an increase in number while density remains the same. Differences in the rates of change in numbers and densities may have different management implications and it is therefore important to address temporal trends in both.

Here we collated information on elephant population estimates and survey areas for northern Botswana, from which we calculated densities and intrinsic growth rates. We compare changes in these parameters over 1973-2004 to clarify temporal trends. Identification of any trends may guide future management actions to control the assumed impact that elephants may have on other species and on the livelihoods of people that live in areas onto which elephants are apparently expanding (Chafota \& Owen-Smith, 1996). 
Table 1 Population estimates (with 95\% confidence limits where available), size of the areas for which the estimates were extrapolated, and elephant densities (with 95\% confidence limits) for both wet and dry seasons, and the source reference. All densities are rounded to the second decimal place.

\begin{tabular}{|c|c|c|c|c|c|c|c|}
\hline \multirow[b]{2}{*}{ Year } & \multicolumn{3}{|l|}{ Wet season } & \multicolumn{3}{|l|}{ Dry season } & \multirow[b]{2}{*}{ Reference } \\
\hline & $\begin{array}{l}\text { Population } \\
\text { estimate }\end{array}$ & $\begin{array}{l}\text { Survey } \\
\text { area }\left(\mathrm{km}^{2}\right)\end{array}$ & $\begin{array}{l}\text { Density } \\
\left(\mathrm{km}^{-2}\right)\end{array}$ & $\begin{array}{l}\text { Population } \\
\text { estimate }\end{array}$ & $\begin{array}{l}\text { Survey } \\
\text { area }\left(\mathrm{km}^{2}\right)\end{array}$ & $\begin{array}{l}\text { Density } \\
\left(\mathrm{km}^{-2}\right)\end{array}$ & \\
\hline 1973 & 11,205 & 20,034 & 0.56 & $\begin{array}{l}8,671 \\
(7,120-10,227)\end{array}$ & 16,782 & $\begin{array}{l}0.52 \\
(0.40-0.61)\end{array}$ & Sommerlatte, 1976 \\
\hline 1974 & 11,027 & 23,365 & 0.47 & $\begin{array}{l}8,542 \\
(6,465-10,619)\end{array}$ & 19,752 & $\begin{array}{l}0.43 \\
(0.33-0.54)\end{array}$ & Sommerlatte, 1976 \\
\hline 1975 & & & & 13,520 & 23,389 & 0.58 & Sommerlatte, 1976 \\
\hline 1981 & 39,511 & 93,400 & 0.42 & & & & Melton, 1985 \\
\hline 1987 & $\begin{array}{l}50,440 \\
(40,352-60,528)\end{array}$ & 119,774 & $\begin{array}{l}0.42 \\
(0.34-0.51)\end{array}$ & $\begin{array}{l}40,530 \\
(26,750-54,310)\end{array}$ & 119,774 & $\begin{array}{l}0.34 \\
(0.22-0.45)\end{array}$ & Gibson et al., 1998 \\
\hline 1989 & $\begin{array}{l}66,051 \\
(45,554-86,548)\end{array}$ & 132,016 & $\begin{array}{l}0.50 \\
(0.35-0.66)\end{array}$ & $\begin{array}{l}59,896 \\
(42,806-76,987)\end{array}$ & 60,878 & $\begin{array}{l}0.98 \\
(0.70-1.26)\end{array}$ & Gibson et al., 1998 \\
\hline 1990 & $\begin{array}{l}49,064 \\
(37,276-60,878)\end{array}$ & 140,387 & $\begin{array}{l}0.35 \\
(0.27-0.43)\end{array}$ & $\begin{array}{l}55,835 \\
(35,635-76,036)\end{array}$ & 67,206 & $\begin{array}{l}0.83 \\
(0.53-1.13)\end{array}$ & Gibson et al., 1998 \\
\hline 1991 & $\begin{array}{l}64,916 \\
(44,864-84,968)\end{array}$ & 150,448 & $\begin{array}{l}0.43 \\
(0.30-0.56)\end{array}$ & $\begin{array}{l}68,771 \\
(50,571-86,971)\end{array}$ & 154,919 & $\begin{array}{l}0.44 \\
(0.33-0.56)\end{array}$ & Gibson et al., 1998 \\
\hline 1993 & $\begin{array}{l}73,901 \\
(44,052-103,751)\end{array}$ & 143,943 & $\begin{array}{l}0.51 \\
(0.31-0.72)\end{array}$ & $\begin{array}{l}79,033 \\
(65,364-92,701)\end{array}$ & 166,236 & $\begin{array}{l}0.48 \\
(0.39-0.56)\end{array}$ & Gibson et al., 1998 \\
\hline 1994 & $\begin{array}{l}54,927 \\
(41,082-68,772)\end{array}$ & $573,694^{1}$ & & $\begin{array}{l}78,304 \\
(61,477-95,131)\end{array}$ & $579,049^{1}$ & & Gibson et al., 1998 \\
\hline 1996 & & & & $\begin{array}{l}100,538 \\
(80,452-120,624)\end{array}$ & $94,554^{2}$ & $\begin{array}{l}1.06 \\
(0.85-1.27)\end{array}$ & DWNP, 1996 \\
\hline 1999 & $\begin{array}{l}106,494 \\
(84,898-128,090)\end{array}$ & $109,284^{2}$ & $\begin{array}{l}0.97 \\
(0.78-1.16)\end{array}$ & $\begin{array}{l}120,603 \\
(98,934-142,274)\end{array}$ & $150,646^{2}$ & $\begin{array}{l}0.80 \\
(0.66-0.94)\end{array}$ & DWNP, 1999a,b \\
\hline 2001 & & & & $\begin{array}{l}116,987 \\
(95,196-138,779)\end{array}$ & $118,257^{2}$ & $\begin{array}{l}0.99 \\
(0.80-1.17)\end{array}$ & DWNP, 2001 \\
\hline 2002 & & & & $\begin{array}{l}123,152 \\
(106,000-140,304)\end{array}$ & $146,059^{2}$ & $\begin{array}{l}0.84 \\
(0.73-0.96)\end{array}$ & DWNP, 2002 \\
\hline 2003 & & & & $\begin{array}{l}109,472 \\
(91,028-127,914)\end{array}$ & $151,054^{2}$ & $\begin{array}{l}0.73 \\
(0.60-0.85)\end{array}$ & DWNP, 2003 \\
\hline 2004 & & & & $\begin{array}{l}151,000 \\
(130,995-171,004)\end{array}$ & $148,202^{2}$ & $\begin{array}{l}1.02 \\
(0.88-1.15)\end{array}$ & DWNP, 2004 \\
\hline
\end{tabular}

${ }^{1}$ Country-wide surveys; survey area is the entire area over which the survey was conducted.

${ }^{2}$ Country-wide surveys; survey area is the area over which elephants were encountered.

\section{Methods}

As most of Botswana's elephants occur in the northern parts of the country (Gibson et al., 1998), we extracted population estimates and survey details for elephants in northern Botswana from published (Melton, 1985; Gibson et al., 1998) and unpublished (Sommerlatte, 1976; DWNP, 1996, 1999a,b, 2001, 2002, 2003, 2004) sources. For all surveys, Method II of Jolly (1969) provided population estimates from fixed-width transects of unequal size sampled without replacement. Surveys were conducted during both dry and wet seasons. We excluded a 1985 survey (Spinage, 1990) for which the methodology was unknown. We also omitted estimates based on partial surveys conducted in 1983, 1984 and 1995 (Gibson et al., 1998) and the 2005 survey conducted by the Department of Wildlife and National Parks
(DWNP). In each case the survey area was that area for which the authors estimated population size. We calculated crude density (Gaston et al., 1999) as the number of elephants per $\mathrm{km}^{2}$ of survey area.

From 1996 to 2004 surveys were country-wide, used standardized methods, and covered areas of 425,694$578,364 \mathrm{~km}^{2}$. For these surveys the DWNP divided the population estimate by the total area covered represented by all transects, irrespective of whether elephants occurred there or not. Because much of the survey area stretched beyond the known elephant range in northern Botswana, we opted to calculate ecological densities (Gaston et al., 1999) for each of these years by dividing the population estimate by the sum of transect areas along which elephants were counted. The 1994 survey covered all of Botswana but we excluded these data from our analysis because Gibson et al. (1998) did not 

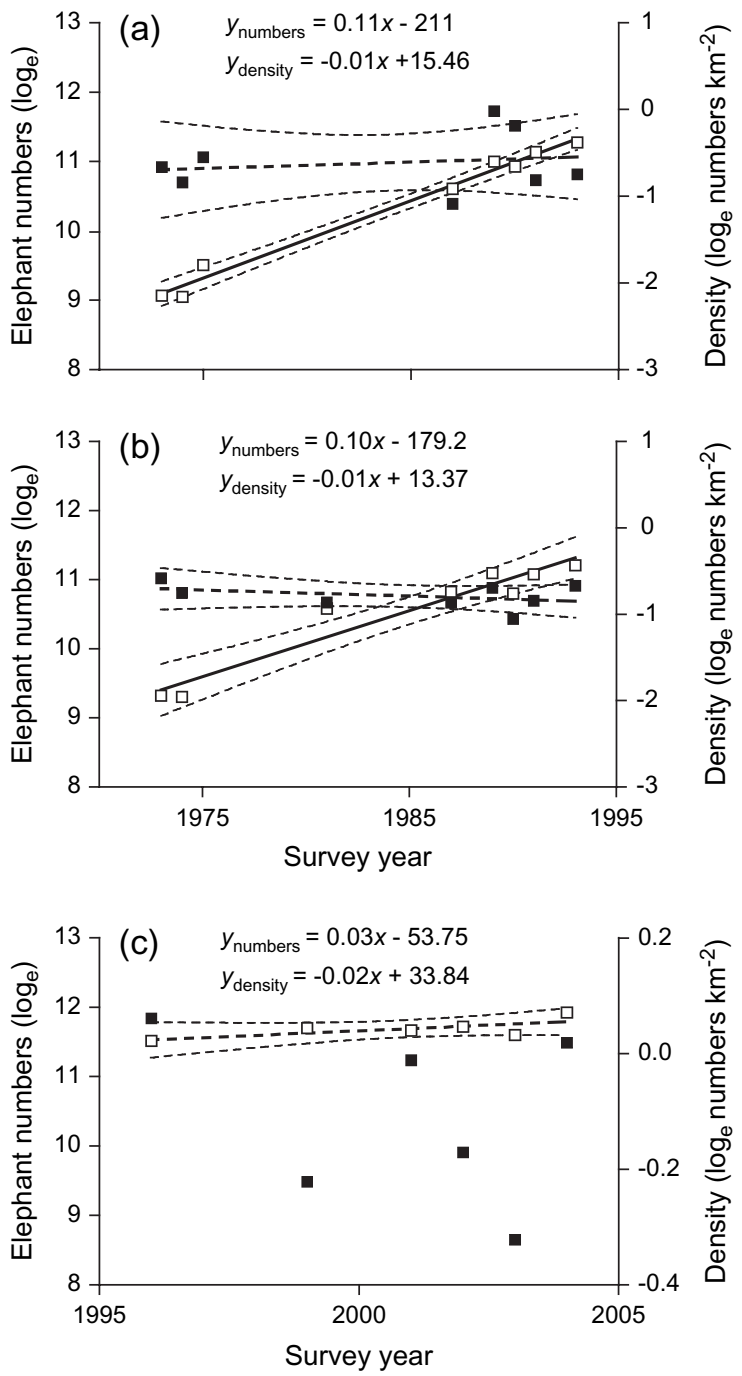

Fig. 1 Linear regressions (with 95\% confidence limits) of the natural logarithm of (a) dry season and (b) wet season elephant numbers (open squares) and densities (solid squares) for

1973-1993, and (c) dry season elephant numbers and densities for 1996-2004. The regression line of density for 1996-2004 had wide confidence limits and is not shown. The slopes of the linear regressions represent intrinsic annual growth rates $(r)$. Solid and stippled regression lines indicate significant and non-significant slopes, respectively. Note the different scaling of the vertical axis.

provide information that could be used to calculate the area over which elephants were encountered.

Following our filtering, the database represented two time periods: the first (1973-1993) comprised population estimates and crude densities and the second (19962004) population estimates and ecological densities. We used least squares regression analysis to test whether the natural logarithm of population estimates (expressed as elephant numbers) and elephant densities increased with time during each of these periods. The slopes and variances yielded estimates of exponential growth and their variances (Caughley, 1977). To accommodate the variances of population estimates in our calculation of population growth rates, we used Monte Carlo simulations (Manly, 1991). This allowed us to estimate growth rates and their variance alternatively. We randomly drew population sizes from normal distributions defined for each population estimate and then recalculated exponential growth as the slope of the linear regression. We repeated this to find 2,000 estimates of population growth from which we calculated variance (Legendre \& Legendre, 1998). From these we could define standard errors for both methods of estimating population growth rate. We also used regression analysis to examine temporal trends in survey areas during each of the time periods.

In our final analyses we fitted two models to the complete time series of population estimates. We fitted an equilibrium model (Boltzman sigmoidal model $y=$ $a+(b-a) /\left[1+e^{\left(v_{50}-x\right) c}\right]$, where $a=$ lower asymptote, $b=$ equilibrium population size or density, $v_{50}=$ the population estimate halfway between the lower asymptote and equilibrium, and $c=$ growth when population size or densities are near $a$ ), and a non-equilibrium model (exponential model, $y=a e^{b x}$, were $a=$ population size at time zero and $b=$ the growth rate) using GraphPad Prism v. 3 (GraphPad Software, San Diego, USA). We relied on the F-test in GraphPad Prism to choose the best model.

\section{Results}

Differences in sampling procedures that affected density estimates required us to analyse the data for the two time periods separately. The first period included eight estimates for dry and wet seasons but not all estimates were for the same years. As we had only one wet season estimate for the second time period, we excluded this period from the analysis of wet season data (Table 1).

Seasonal differences in estimates were not consistent (paired $t$-test $t=0.39, \mathrm{df}=7, \mathrm{P}=0.71$ ). From 1973 to 1993 elephant numbers and densities were 8,542-79,033 and $0.34-0.98 \mathrm{~km}^{-2}$, respectively. From 1996 to 2004 elephant numbers were 100,538-151,000 and densities 0.73-1.06 km $\mathrm{km}^{-2}$. Variances of population estimates for 1973-1993 differed for both the dry $\left(F_{\max }=168.55\right.$, $\mathrm{df}=5, \mathrm{P}<0.05)$ and wet seasons $\left(F_{\max }=8.76, \mathrm{df}=4\right.$, $\mathrm{P}<0.05)$. However, variances for population estimates over 1996-2004 were similar $\left(F_{\max }=1.61, \mathrm{df}=4\right.$, $\mathrm{P}=0.15)$.

Population growth rates calculated by regression analysis from population estimates for 1973-1993 were 11.2 \pm SE $0.53 \%$ and $9.6 \pm$ SE $1.11 \%$ (Fig. 1a,b; Table 2) for the dry and wet seasons, respectively. Monte Carlo simulations 
Table 2 Linear regression analysis and Monte Carlo simulations used to calculate intrinsic growth rates $(r)$, expressed as a percentage. The slopes of the regression lines represent $r$. Growth rates in elephant numbers and densities are calculated separately for wet and dry season and for 1973-1993 and 1996-2004. Both numbers and densities were $\log _{\mathrm{e}}$ transformed for the linear regression analyses. Significant regressions are in bold.

\begin{tabular}{|c|c|c|c|c|c|c|c|c|c|c|c|c|}
\hline & \multirow[b]{2}{*}{ Years } & \multirow[b]{2}{*}{ Simulation } & \multicolumn{5}{|c|}{ Wet season } & \multicolumn{5}{|c|}{ Dry season } \\
\hline & & & $r(\%)$ & SE & $F$ & $\mathrm{df}$ & $\mathrm{P}$ & $r(\%)$ & SE & $F$ & $\mathrm{df}$ & $\mathrm{P}$ \\
\hline \multirow[t]{4}{*}{ Numbers } & \multirow[t]{2}{*}{ 1973-1993 } & Linear & 9.6 & 1.11 & \multirow[t]{4}{*}{73.94} & \multirow[t]{4}{*}{1,6} & \multirow[t]{4}{*}{$<0.0001$} & 11.2 & 0.53 & 435.7 & 1,6 & $<0.0001$ \\
\hline & & Monte Carlo & 9.5 & 0.54 & & & & 11.1 & 0.51 & & & \\
\hline & \multirow[t]{2}{*}{ 1996-2004 } & Linear & & & & & & 3.27 & 1.7 & 3.83 & 1,4 & 0.12 \\
\hline & & Monte Carlo & & & & & & 3.37 & 1.4 & & & \\
\hline \multirow[t]{4}{*}{ Densities } & \multirow[t]{2}{*}{ 1973-1993 } & Linear & -0.72 & 0.7 & \multirow[t]{4}{*}{1.00} & \multirow[t]{4}{*}{1,6} & \multirow[t]{4}{*}{0.36} & 0.75 & 1.7 & 0.20 & 1,6 & 0.67 \\
\hline & & Monte Carlo & -0.81 & 0.6 & & & & 0.72 & 0.5 & & & \\
\hline & \multirow[t]{2}{*}{ 1996-2004 } & Linear & & & & & & -0.17 & 2.47 & 0.47 & 1,4 & 0.53 \\
\hline & & Monte Carlo & & & & & & -1.63 & 1.38 & & & \\
\hline
\end{tabular}

predicted growth rates of $11.1 \pm$ SE $0.51 \%$ during the dry and $9.5 \pm$ SE $0.54 \%$ during the wet season (Table 2). In contrast, growth rates in elephant densities for the same time period did not differ significantly from zero (Fig. $1 \mathrm{a}, \mathrm{b}$; Table 2). Growth rates for population estimates and densities differed significantly $\left(F_{d r y}=34.0, \mathrm{df}=1,6\right.$, $\left.\mathrm{P}_{\text {dry }}<0.0001 ; F_{\text {wet }}=60.52, \mathrm{df}=1,6, \mathrm{P}_{\text {wet }}<0.0001\right)$.

From 1996 to 2004 neither elephant numbers nor densities changed significantly (Fig. 1c; Table 2). Estimated population size averaged 120,292 \pm SE 13,990 and mean elephant density was $0.91 \pm$ SE $0.06 \mathrm{~km}^{-2}$.

From 1973 to 1993 the size of the survey area increased significantly over time during both the dry and wet seasons $\left(F_{d r y}=15.10, \mathrm{df}=1,6, \mathrm{P}_{d r y}<0.01 ; F_{\text {wet }}=205.30\right.$, $\mathrm{df}=1,6, \mathrm{P}_{\text {wet }}<0.0001$; Fig. 2a,b). However, since 1996 the size of the area over which elephants were encountered during surveys (averaging 134,800 \pm SE 9,513 $\mathrm{km}^{2}$ ) did not change significantly $(F=4.94, \mathrm{df}=1,4$, $\mathrm{P}=0.09$; Fig. 2c). However, statistical power for this regression is relatively low $(1-\beta=0.37)$, resulting in an increased probability of making a Type 2 error, i.e. falsely accepting that the size of the area over which elephants were encountered during surveys did not change.

The time series combining dry season elephant numbers from both periods were best described by an equilibrium model (Boltzman sigmoidal; $F=4.50, \mathrm{df}=11$, $\mathrm{P}<0.05, R^{2}=0.97$; Fig. 3). This suggests that, as elephant numbers increased over time, population growth rate declined until it did not differ significantly from zero.

\section{Discussion}

Between 200,000 and 400,000 elephants may have lived in Botswana at the beginning of the 19th century (Campbell, 1990), mostly in the north. In the 80 years that followed, uncontrolled commercial hunting for ivory exterminated elephants from southern Botswana and reduced their population to a mere remnant in the far north (Campbell, 1990). The reinvasion of the region by the tsetse fly, the subsequent collapse of the cattle population, and improved protection (Melton, 1985) caused elephants to reappear along the Chobe River by the late 1940s (Sommerlatte, 1976). Hearsay, suggesting that numbers increased, was supported by spoor and direct ground surveys carried out over 1963-1970 (Sommerlatte, 1976; Campbell, 1990).

The first aerial counts in 1973-1975 were motivated by concerns that elephants may become overabundant in this region (Sommerlatte, 1976). Since then, elephants in northern Botswana have been counted repeatedly, albeit at varying time intervals and survey intensities (Melton, 1985; Gibson et al., 1998, and sources therein, including KCS, 1984, 1985; Work, 1986; Gavor, 1987; Calef, 1988, 1990; Craig, 1991, 1996; Bonifica, 1992; DWNP, 1993, 1995; ULG, 1993, 1994). However, survey methods were standardized in the mid 1990s (DWNP, 1996, 1999a,b, 2001, 2002, 2003, 2004).

The census data from 1973 to 1993 revealed a significant increase in elephant numbers in northern Botswana. During this period mean annual growth rate exceeded the maximum $7 \%$ estimated for elephants (Calef, 1988). This may have been because of elephants dispersing from Zimbabwe, Zambia, Angola and Namibia (Campbell, 1990; Gibson et al., 1998). In contrast, the growth rate for elephant densities during the same time did not differ from zero. How can this anomaly be explained?

A key constraint in the analysis of these temporal trends is that the surveys were carried out in areas that differ in size (surveyed areas increased from 1973 to 1993 but remained relatively constant afterwards). There are two possible explanations for the different trends in numbers and densities recorded before 1993. The first is that both the range of the population and the population size were stable over time and that we recorded an 

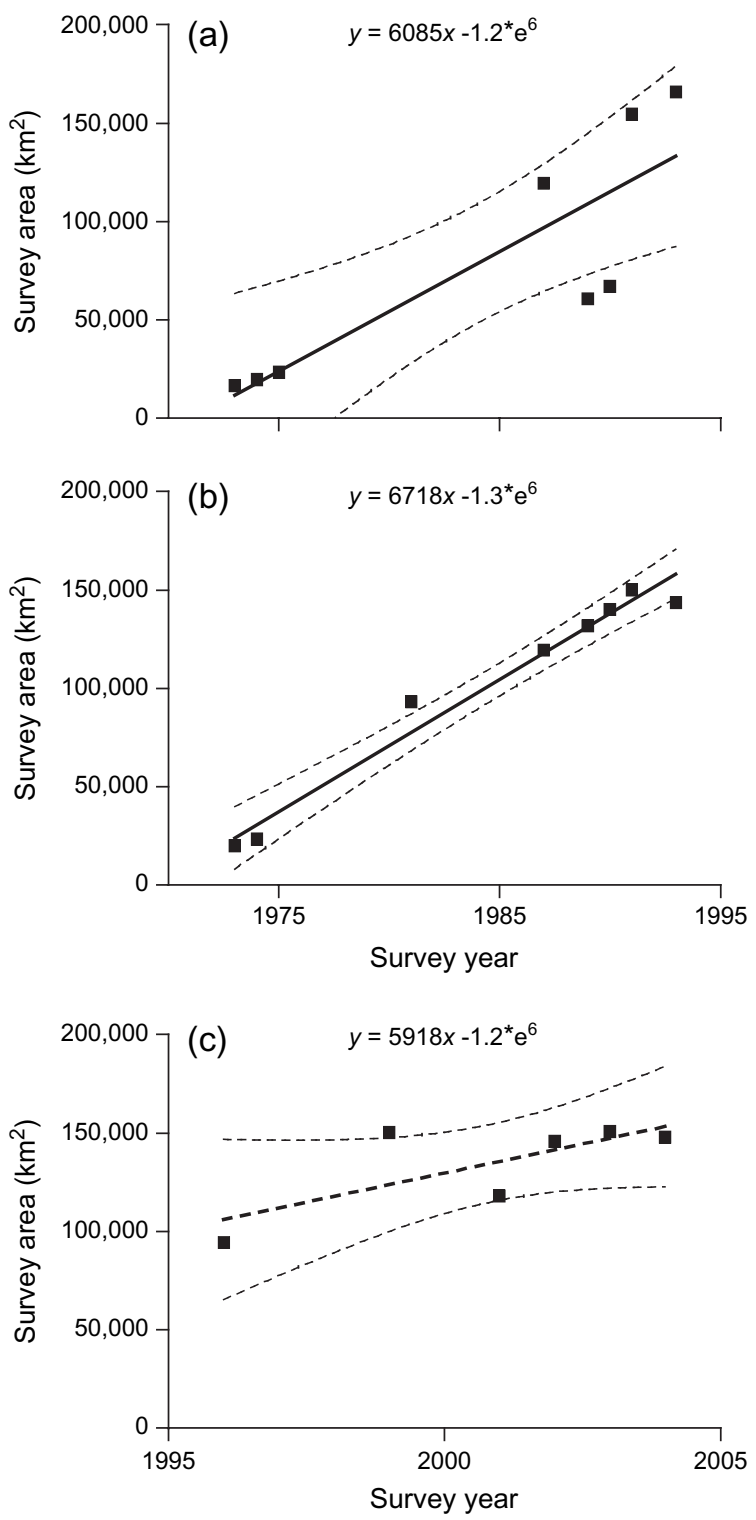

Fig. 2 Linear regressions (with 95\% confidence limits) of (a) dry and (b) wet season survey area sizes for 1973-1993, and (c) dry season survey area sizes for 1996-2004. Solid and stippled regression lines indicate significant and non-significant slopes, respectively.

increase in numbers while densities remained constant; the initial surveys focused on only a fraction of the area in which elephants occur, and later survey areas increased until the entire range of the population was included (Fig. 4a). The second explanation is that both the range of the population and elephant numbers increased over time and surveys focused on those areas in which elephants were relatively abundant. Surveys thus covered larger areas over time in response to the expansion of elephant range and, as a result, more

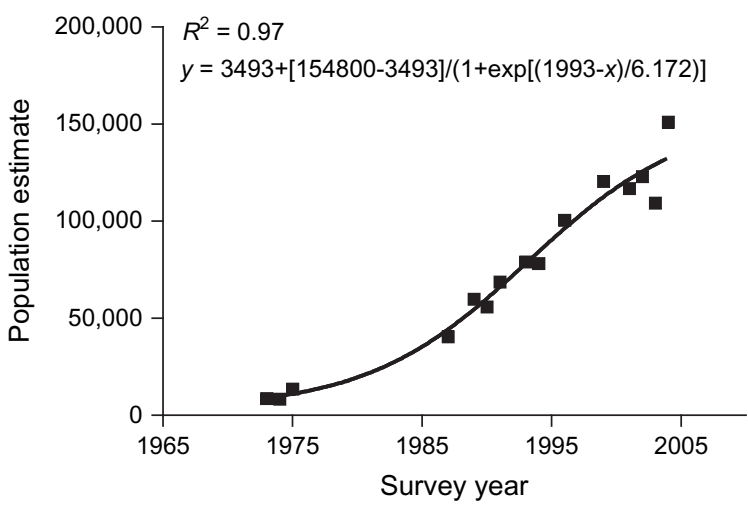

Fig. 3 Dry season elephant numbers for 1973-2004. The data converged best to a Boltzman sigmoidal curve (see text for details), suggesting that numbers are currently stabilizing.

elephants were counted in larger areas, resulting in an increase in estimates of elephant numbers while densities remained relatively stable (Fig. 4b). We cannot unequivocally distinguish between the two explanations. However, given the historical accounts of the distribution of elephants in Botswana (Sommerlatte, 1976; Campbell, 1990) it seems likely that this population increased and expanded its range from 1973 to 1993, i.e. in recovery following a precipitous decline.

Changes in surveyed areas do not constrain the trends recorded from 1996 to 2004 because the DWNP conducted country-wide surveys that included the entire range of Botswana's elephants. Elephant numbers for this period were therefore comparable between years, and neither the number of elephants nor densities changed significantly. This is in contrast to some earlier reports and deductions that implied a continuing increase of the northern Botswana population (Blanc et al., 2003, 2005; Cumming \& Jones, 2005).

If the first explanation is correct, then the stabilization of numbers could be the result of surveys having reached the periphery of the range of the population. However, if the second explanation is correct then the onset of density-dependence (Sinclair, 2003; OwenSmith et al., 2006; Chamaillé-Jammes et al., 2007) could be responsible for the apparent stabilization in numbers. The underlying mechanisms for any such stabilization are not yet clear but may result from density-dependent dispersal. Dispersal may also explain the abrupt increase in numbers from 2003 to 2004 (Fig. 3; Table 1). During this period surveys used standardized methods, yielding estimates with similar levels of precision. Therefore, the differences in population size may be the result of movements by elephants across national boundaries rather than variation in census error or population increase through reproduction. These matters need further investigation, most importantly by 
(a)
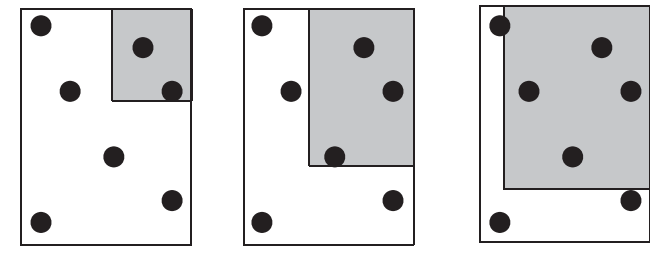

(b)

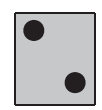

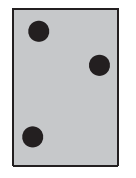
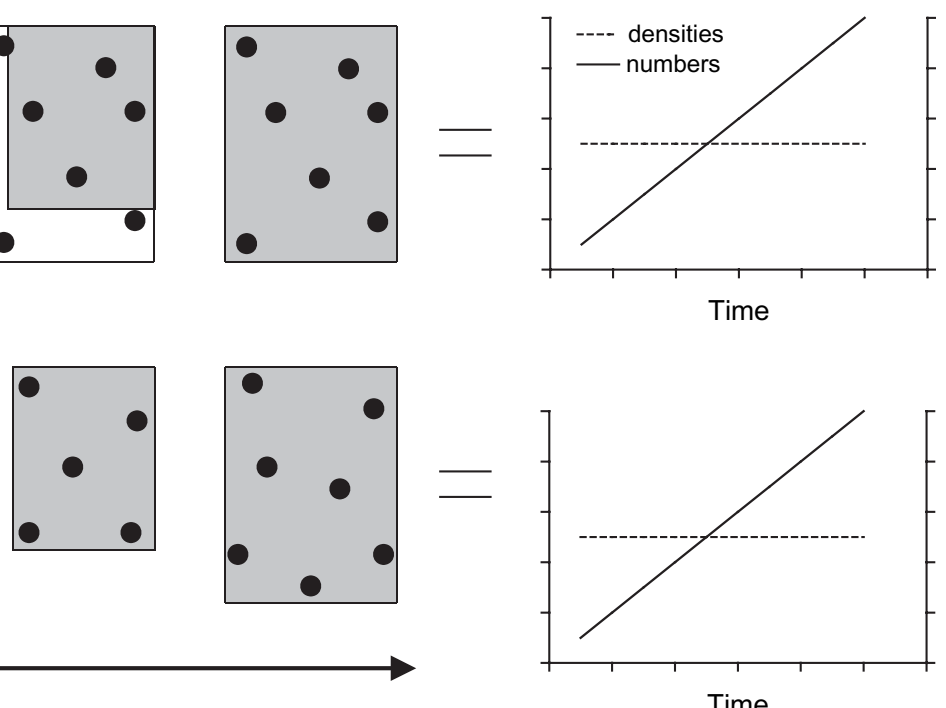

Time

Time

Fig. 4 Simplified illustration of the two possible explanations for the trends in numbers and densities over time observed for the northern Botswana elephant population. Solid dots depict individuals and grey shading survey areas. The explanations differ in that the first (a) proposes a stable range and population size over time, whereas the second (b) suggests that the population increased in size and expanded its range over time (see text for further details).

making use of synchronized counts across countries and population boundaries. Density-dependent stabilization, if it occurs, would be of particular importance for conservation management. For instance, should the levelling off in population size be induced by density, a reduction in numbers would merely be followed by an increase in growth rate.

Irrespective of which one of the two explanations is correct, it appears that elephant numbers in northern Botswana have begun to stabilize despite a high growth rate noted previously (Gibson et al., 1998). Our results support this notion. An equilibrium model best described the trend in dry season elephant numbers over time, suggesting that population growth decreased with an increase in population size. Analyses of changes in elephant distribution and seasonal variability in densities calculated from survey data may identify areas where elephant impact and conflict is most intense. In addition, analyses that compare count-based growth rates and demographically derived growth rates may clarify the contribution of emigration and immigration to local population sizes.

Trends aside, the expansion of the elephant population into its traditional distributional range (Campbell, 1990; Gibson et al., 1998), now inhabited by people, is a matter of concern because the livelihoods of people are influenced by the presence of elephants (Jackson et al., 2008). However, the expansion of the range has the benefit of ameliorating impact on vegetation by allowing seasonal changes in habitat utilization through the restoration of traditional migratory patterns (van Aarde et al., 2006), and also helps maintain metapopulation dynamics and caters for local instabilities (van Aarde \& Jackson, 2007). The regional management of landscapes and spatial utilization could therefore replace the need for the local management of numbers. The DWNP has expressed concern about the possible impact that elephants may have on biodiversity and included this as a criterion for management action in Botswana's Elephant Management Plan (DWNP, 1991, in Herremans, 1995). However, no culling of elephants has taken place in Botswana to date and the management plan is currently under review. Based on our recent satellite tracking studies and on the work of Verlinden \& Gavor (1998) we know that northern Botswana's elephants are part of a much larger regional population. Any efforts to reduce Botswana's elephants to ameliorate local impacts may therefore have regional effects on dispersal and hence on apparent local population trends, as has been illustrated for elephants in the Kruger National Park (van Aarde et al., 1999). This may nullify efforts to lower impact on local vegetation and other species.

\section{Acknowledgements}

We would like to thank the Department of Wildlife and National Parks, Botswana, for supporting our initiatives 
and for providing us with unpublished census data. Our research in Botswana is financially supported by the University of Pretoria, the Peace Parks Foundation, the International Fund for Animal Welfare, and the African Wilderness Programme of Conservation International.

\section{References}

Bengis, R.G. (1996) Elephant population control in African national parks. Pachyderm, 22, 83-86.

Ben-Shahar, R. (1997) Elephants and woodlands in northern Botswana: how many elephants should be there? Pachyderm, 23, 41-43.

Blanc, J.J., Barnes, R.F.W., Craig, C.G., Douglas-Hamilton, I., Dublin, H.T., Hart, J.A. \& Thouless, C.R. (2005) Changes in elephant numbers in major savanna populations in eastern and southern Africa. Pachyderm, 38, 19-28.

Blanc, J.J., Thouless, C.R., Hart, J.A., Dublin, H.T., DouglasHamilton, I., Craig, C.G. \& Barnes, R.F.W. (2003) African Elephant Status Report 2002. An Update from the African Elephant Database. IUCN/SSC African Elephant Specialist Group, Gland, Switzerland.

Calef, G.W. (1988) Maximum rate of increase in the African elephant. African Journal of Ecology, 26, 323-328.

Campbell, A.C. (1990) History of elephants in Botswana. In The Future of Botswana's Elephants. Proceedings of Kalahari Conservation Society Symposium, 1990 (eds P. Hancock, M. Cantrell \& S. Hughes), pp. 5-15. The Kalahari Conservation Society/Department of Wildlife and National Parks, Gaborone, Botswana.

Caughley, G. (1977) Analysis of Vertebrate Populations. John Wiley \& Sons, New York, USA.

Chafota, J. \& Owen-Smith, N. (1996) Options for the management of elephants in northern Botswana. Pachyderm, 22, 67-73.

Chamaillé-Jammes, S., Valeix, M. \& Hervé, F. (2007) Managing heterogeneity in elephant distribution: interactions between elephant population density and surface-water availability. Journal of Applied Ecology, 44, 625-633.

Colegrave, R.K., Lungu, E.M. \& Muwezwa, M.E. (1992) What is happening to the elephants in Botswana? Revue de Bio Matematique, 30, 49-55.

Cumming, D. \& Jones, B. (2005) Elephants in Southern Africa: Management Issues and Options. WWF-SARPO Occasional Paper No. 11. WWF-SARPO, Harare, Zimbabwe.

DWNP (Department of Wildlife and National Parks) (1996) Aerial Census of Wildlife and some Domestic Animals in Botswana. Dry Season 1996. Department of Wildlife and National Parks, Monitoring Unit Research Division, Gaborone, Botswana.

DWNP (Department of Wildlife and National Parks) (1999a) Aerial Census of Wildlife and some Domestic Animals in Botswana. Dry Season 1999. Department of Wildlife and National Parks, Monitoring Unit Research Division, Gaborone, Botswana.

DWNP (Department of Wildlife and National Parks) (1999b) Aerial Census of Wildlife and some Domestic Animals in Botswana. Wet Season 1999. Department of Wildlife and National Parks, Monitoring Unit Research Division, Gaborone, Botswana.

DWNP (Department of Wildlife and National Parks) (2001) Aerial Census of Animals in Botswana. Dry Season 2001.
Department of Wildlife and National Parks, Monitoring Unit Research Division, Gaborone, Botswana.

DWNP (Department of Wildlife and National Parks) (2002) Aerial Census of Animals in Botswana. Dry Season 2002. Department of Wildlife and National Parks, Monitoring Unit Research Division, Gaborone, Botswana.

DWNP (Department of Wildlife and National Parks) (2003) Aerial Census of Animals in Botswana. Dry Season 2003. Department of Wildlife and National Parks, Monitoring Unit Research Division, Gaborone, Botswana.

DWNP (Department of Wildlife and National Parks) (2004) Aerial Census of Animals in Botswana. Dry Season 2004. Department of Wildlife and National Parks, Monitoring Unit Research Division, Gaborone, Botswana.

Gaston, K.J., Blackburn, T.M. \& Gregory, R.D. (1999) Does variation in census area confound density comparisons? Journal of Applied Ecology, 36, 191-204.

Gibson, D.S., Craig, G.C. \& Masogo, R.M. (1998) Trends of the elephant population in northern Botswana from aerial survey data. Pachyderm, 25, 14-27.

Grainger, M., van Aarde, R.J. \& Whyte, I. (2005) Landscape heterogeneity and the use of space by elephants in the Kruger National Park, South Africa. African Journal of Ecology, 43, 369-375.

Herremans, M. (1995) Effects of woodland modification by African elephant Loxodonta africana on bird diversity in northern Botswana. Ecography, 18, 440-454.

Jackson, T.P., Mosojane, S., Ferreira, S. \& van Aarde, R.J. (2008) Solutions for elephant Loxodonta africana crop raiding in northern Botswana: moving away from symptomatic approaches. Oryx , 42, 83-91.

Jolly, J.M. (1969) Sampling methods for aerial censuses of wildlife populations. East African Agriculture and Forestry Journal, 34, 46-49.

Legendre, L. \& Legendre, P. (1998) Numerical Ecology, 2nd edition. Elsevier, Amsterdam, The Netherlands.

Manly, B.F.J. (1991) Randomization and Monte Carlo Methods in Biology. Chapman \& Hall, London, UK.

Melton, D.A. (1985) The status of elephants in northern Botswana. Biological Conservation, 31, 317-333.

Owen-Smith, N., Kerley, G.I.H., Page, B., Slotow, R. \& van Aarde, R.J. (2006) A scientific perspective on the management of elephants in Kruger National Park and elsewhere. South African Journal of Science, 102, 389-394.

Sinclair, A.R.E. (2003) Mammal population regulation, keystone processes and ecosystem dynamics. Philosophical Transactions of the Royal Society London B, 358, 1729-1740.

Skarpe, C., Aarrestad, P.A., Andreassen, H.P., Dhillion, S.S., Dimakatso, T., Du Toit, J.T. et al. (2004) The return of the giants: ecological effects of an increasing elephant population. Journal of the Royal Swedish Academy of Sciences, 33 276-282.

Sommerlatte, M.W. (1976) A Survey of Elephant Populations in North-eastern Botswana. Department of Wildlife and National Parks, UNDP/ FAO Project 72/020, Wildlife Management and Utilisation in Botswana. Government Printer, Gaborone Botswana.

Spinage, C.A. (1990) Botswana's problem elephants. Pachyderm, 13, 14-20.

Van Aarde, R.J. \& Jackson, T.P. (2007) Megaparks for metapopulations: addressing the causes of locally high elephant numbers in southern Africa. Biological Conservation, 134, 289-297. 
Van Aarde, R.J., Jackson, T.P. \& Ferreira, S.M. (2006)

Conservation science and elephant management in southern Africa. South African Journal of Science, 102, 385-388.

Van Aarde, R., Whyte, I. \& Pimm, S. (1999) Culling and dynamics of the Kruger National Park African elephant population. Animal Conservation, 2, 287-294.

Verlinden, A. \& Gavor, I.K.N. (1998) Satellite tracking of elephants in northern Botswana. African Journal of Ecology, 36, 105-116.

\section{Biographical sketches}

Jessica Junker's research focuses on large mammal temporal population dynamics and their conservation. Rudi J. van Aarde, Director of the Conservation Ecology Research Unit (CERU), focuses on the restoration of populations and communities as a contribution to conservation. At present, CERU's research on elephants covers populations in Botswana, Malawi, Mozambique, Namibia, South Africa, Zambia and Zimbabwe. Sam M. Ferreira's research focuses on mammal and bird conservation biology with an emphasis on temporal dynamics and the factors influencing these. $\mathrm{He}$ also has a keen interest in restoration ecology and the application of theoretical ecology to address ecological problems. He currently coordinates aspects of the Elephant Programme at CERU. 